\title{
Erratum to: Plant water use strategies in the Shapotou artificial sand-fixed vegetation of the southeastern margin of the Tengger Desert, northwestern China
}

ZHAO Liang-ju1,2* (Dhttps://orcid.org/oooo-ooo1-7445-3916; Мe-mail: zhlj@nwu.edu.cn WANG Xiao-gang1 (iDhttps://orcid.org/oooo-ooo2-6691-9728; e-mail: 505993849@qq.com ZHANG Yu-cui3* D https://orcid.org/oooo-ooo3-3659-9142; e-mail: yczhang@sjziam.ac.cn XIE Cong1 (D)https://orcid.org/oooo-0oo3-2408-9110; e-mail: 201720806@stumail.nwu.edu.cn LIU Quan-yu1,4 Đhttps://orcid.org/oooo-0oo2-3558-8348; e-mail: 907721965@qq.com

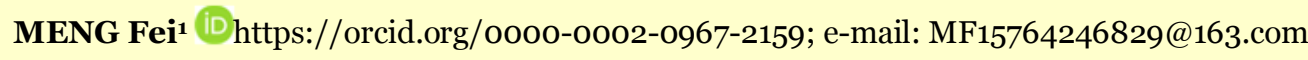

* Corresponding author

1 Key Laboratory of Earth Surface System and Environmental Carrying Capacity, College of Urban and Environmental Sciences, Northwest University, Xi'an 710127, China

2 Northwest Institute of Eco-Environment and Resources, Chinese Academy of Sciences, Lanzhou 730ooo, China

3 Key Laboratory of Agricultural Water Resources, Center for Agricultural Resources Research, Institute of Genetics and Developmental Biology, Chinese Academy of Sciences, Shijiazhuang 050021, China

4 College of Tourism and Environment, Ankang University, Ankang 7250oo, China

Citation: Zhao LJ, Wang XG, Zhang YC, et al. (2019) Erratum to: Plant water use strategies in the Shapotou artificial sand-fixed vegetation of the southeastern margin of the Tengger Desert, northwestern China. Journal of Mountain Science 16(6). https://doi.org/10.1007/s11629-019-5472-1

(C) Science Press, Institute of Mountain Hazards and Environment, CAS and Springer-Verlag GmbH Germany, part of Springer Nature 2019

Erratum to: J. Mt. Sci. (2019) 16(4): 898-908

https://doi.org/10.1007/s11629-018-5028-9

The horizontal and vertical coordinates in Figure 6 is incorrect in the original article. The figure should be changed to the figure below. 


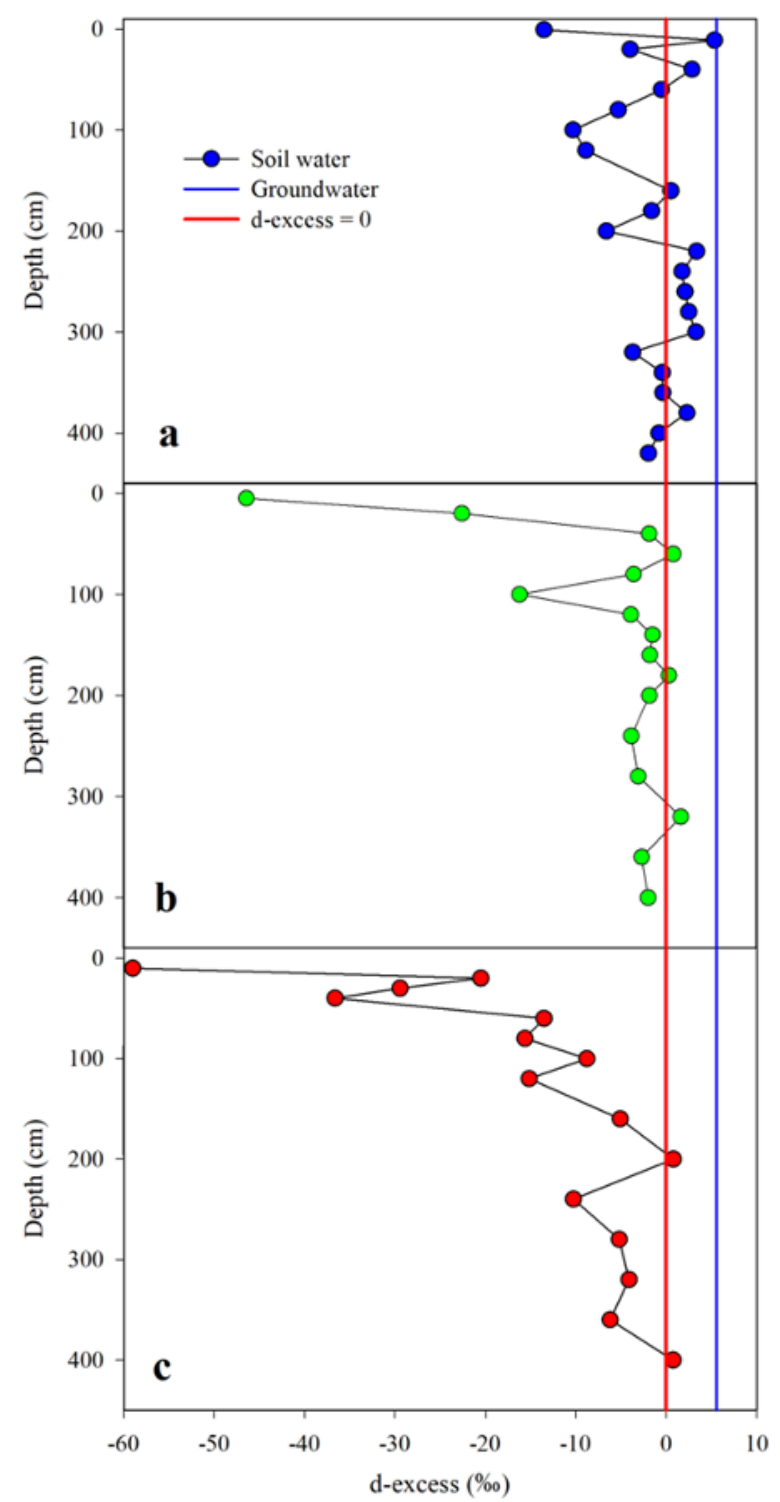

Figure 6 Variations of soil water d-excess in whole soil profile at Shapotou in January (a), May (b) and August (c), 2008.

The online version of the original article can be found at https://doi.org/10.1007/s11629-018-5028-9. 